UPMC Center for

Health Security

\title{
Singapore-US Strategic Dialogue on Biosecurity
}




\section{Report Documentation Page}

Form Approved

OMB No. 0704-0188

Public reporting burden for the collection of information is estimated to average 1 hour per response, including the time for reviewing instructions, searching existing data sources, gathering and maintaining the data needed, and completing and reviewing the collection of information. Send comments regarding this burden estimate or any other aspect of this collection of information,

including suggestions for reducing this burden, to Washington Headquarters Services, Directorate for Information Operations and Reports, 1215 Jefferson Davis Highway, Suite 1204, Arlington

VA 22202-4302. Respondents should be aware that notwithstanding any other provision of law, no person shall be subject to a penalty for failing to comply with a collection of information if it

does not display a currently valid OMB control number.

1. REPORT DATE

JUL 2014

4. TITLE AND SUBTITLE

Singapore-US Strategic Dialogue on Biosecurity

6. $\operatorname{AUTHOR}(\mathrm{S})$

7. PERFORMING ORGANIZATION NAME(S) AND ADDRESS(ES)

UPMC Center for Health Security,621 E. Pratt Street Suite 210,Baltimore,MD,21202

9. SPONSORING/MONITORING AGENCY NAME(S) AND ADDRESS(ES)

\section{DATES COVERED}

00-00-2014 to 00-00-2014

5a. CONTRACT NUMBER

5b. GRANT NUMBER

5c. PROGRAM ELEMENT NUMBER

5d. PROJECT NUMBER

5e. TASK NUMBER

5f. WORK UNIT NUMBER

8. PERFORMING ORGANIZATION REPORT NUMBER

10. SPONSOR/MONITOR'S ACRONYM(S)

11. SPONSOR/MONITOR'S REPORT NUMBER(S)

12. DISTRIBUTION/AVAILABILITY STATEMENT

Approved for public release; distribution unlimited

13. SUPPLEMENTARY NOTES

14. ABSTRACT

15. SUBJECT TERMS

16. SECURITY CLASSIFICATION OF:

a. REPORT

unclassified b. ABSTRACT

unclassified c. THIS PAGE

unclassified
17. LIMITATION OF ABSTRACT

Same as

Report (SAR)
18. NUMBER 19a. NAME OF

OF PAGES

22 


\section{UPMC Center for Health Security Project Team}

\section{Gigi Kwik Gronvall, PhD}

Senior Associate

Sanjana Ravi, MPH

Analyst

Ryan Morhard, JD

Associate

Anita Cicero, JD

Chief Operating Officer and Deputy Director

Tom Inglesby, MD

Chief Executive Officer and Director

\section{Project Sponsor}

Project on Advanced Systems and Concepts for Countering Weapons of Mass Destruction Naval Postgraduate School

Defense Threat Reduction Agency*

\footnotetext{
* This publication results from research supported by the Naval Postgraduate School's Project on Advanced Systems and Concepts for Countering Weapons of Mass Destruction (PASCC) via Assistance Grant/Agreement No. N00244-14-1-0040 awarded by the NAVSUP Fleet Logistics Center San Diego (NAVSUP FLC San Diego). The views expressed in written materials of publications, and/or made by speakers, moderators, and presenters, do not necessarily reflect the official policies of the Naval Postgraduate School nor does mention of trade names, commercial practices, or organizations imply endorsement by the U.S. Government.
} 


\section{Singapore-US Strategic Dialogue on Biosecurity}

\section{Table of Contents}

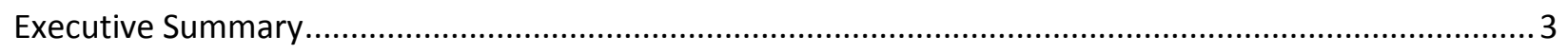

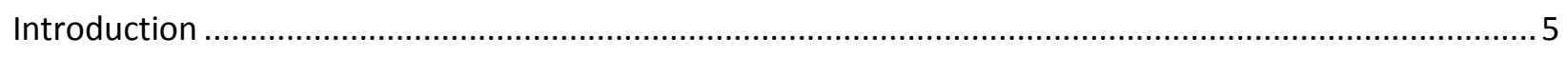

Findings

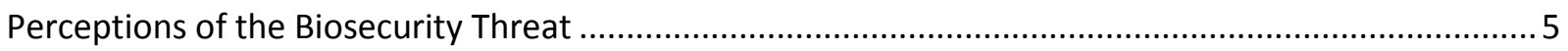

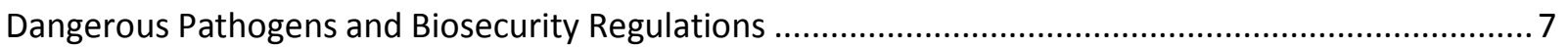

National Biosecurity Challenges and Potential Benefits Emanating from Rapid Growth of the Life

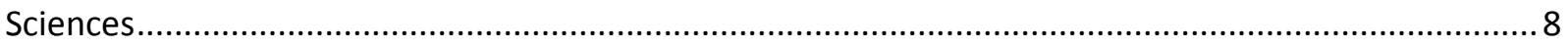

Biosafety and Biosecurity Infrastructure and Mitigating Against Insider Threats............................... 10

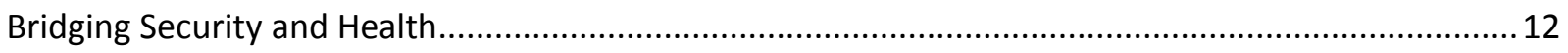

Building Biosecurity in the Asia-Pacific Region ............................................................................. 14

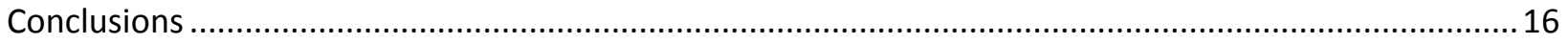

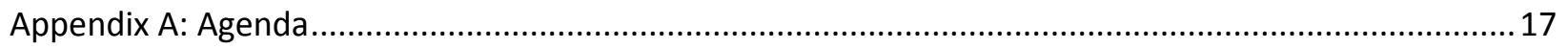

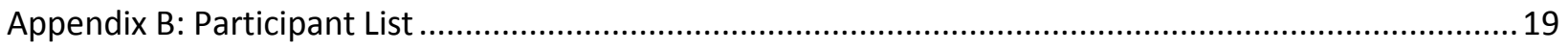

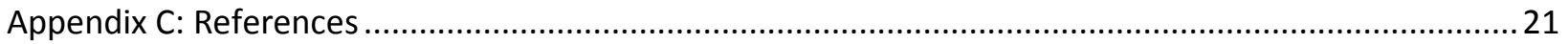




\section{Executive Summary}

Singapore is poised to be a critical partner to the US in minimizing biosecurity challenges in Southeast Asia. As a nation, it is vulnerable to both emerging infectious disease and potential terrorism in the region. In addition to its geographical importance within the Asia-Pacific region, Singapore is a rising powerhouse in biotechnology, having invested \$13.2B in biotech R\&D from 2011-2015. As a result, it has become an attractive site for international biotechnology companies like Novartis, as well as world-class research universities. It is home to government and academic expertise capable of identifying and responding to biosecurity challenges. Its expertise is, in many ways, complementary to that of the US in these realms.

For these reasons, the UPMC Center for Health Security hosted the first-ever Track II biosecurity dialogue between the United States and Singapore. The meeting took place in June 2014 in Washington, DC and was supported by the Project on Advanced Systems and Concepts for Countering WMD (PASCC), sponsored by the US Defense Threat Reduction Agency (DTRA).

Important conclusions came from the inaugural meeting:

1. There are differences in biosecurity priorities between the two countries. While there is broad agreement on the importance of biosecurity as a national issue, the two countries have different top level concerns. Singapore's major concerns are largely related to infectious disease outbreaks with epidemic potential, as Singapore is an island with heavy, daily traffic as a result of trade, tourism, and workers entering from Indonesia and Malaysia. Singapore is also cognizant of terrorist group activities in the region. It sees the need for, and has invested in, biodetection and biodefense capabilities, though many Singaporean security experts perceive the bioterrorism threat to be low. The US, shaped by its own experiences with terrorism and disease outbreaks, has serious national concerns regarding both deliberate biological threats as well as the threats posed by naturally occurring epidemic disease.

2. Singapore and the US should build on their existing, strong relationship in ways that strengthen biosecurity in the Asia-Pacific region. Singapore and the US share concerns about the seriousness of biological threats to their respective nations, and so have clear reasons for partnership and collaboration in this area. This kind of deepened partnership would have value for both countries.

3. The Global Health Security Agenda (GHSA), a 2014 White House-led global initiative, may provide an opportunity for enhanced cooperation between the US and Singapore. Singapore is not yet a member, but was invited to participate in the GHSA at the meeting by Andrew Weber, Assistant Secretary of Defense for Nuclear, Chemical, and Biological Defense Programs. Singaporean participants were supportive of this possibility and noted that collaboration between the health and security communities, an integral component of the GHSA, is already quite common in Singapore. 
4. Singapore and the US share interests in biosafety and biosecurity training, and are concerned about the maintenance of biosafety high-containment laboratories, particularly in lessresourced nations. Singapore's perspective is that a chain is only as strong as its weakest link. The country has therefore assumed the responsibility of helping its regional neighbors achieve high levels of biosafety and biosecurity, and considers this to be an important measure for ensuring Singaporean national security. Like the US, Singapore is moving to professionalize and expand the biosafety field. Improving biosecurity and biosafety also includes an assessment of what planning in both countries contributes to reducing the insider threat.

5. Singaporean attendees strongly encouraged expanding this strategic dialogue to include participants from other nations to better explore regional biosecurity and biosafety issues from a multilateral perspective and invite new, diverse perspectives. It was noted that the debate over "viral sovereignty" and the closure of the NAMRU-2 lab in Indonesia has resulted in an ongoing level of regional distrust -- both of the US and Singapore. Much can be done constructively to engage with countries in the region on biosecurity issues. The goal will be to include Indonesia and Malaysia in a strategic dialogue on biosecurity with the US and Singapore, starting in 2015.

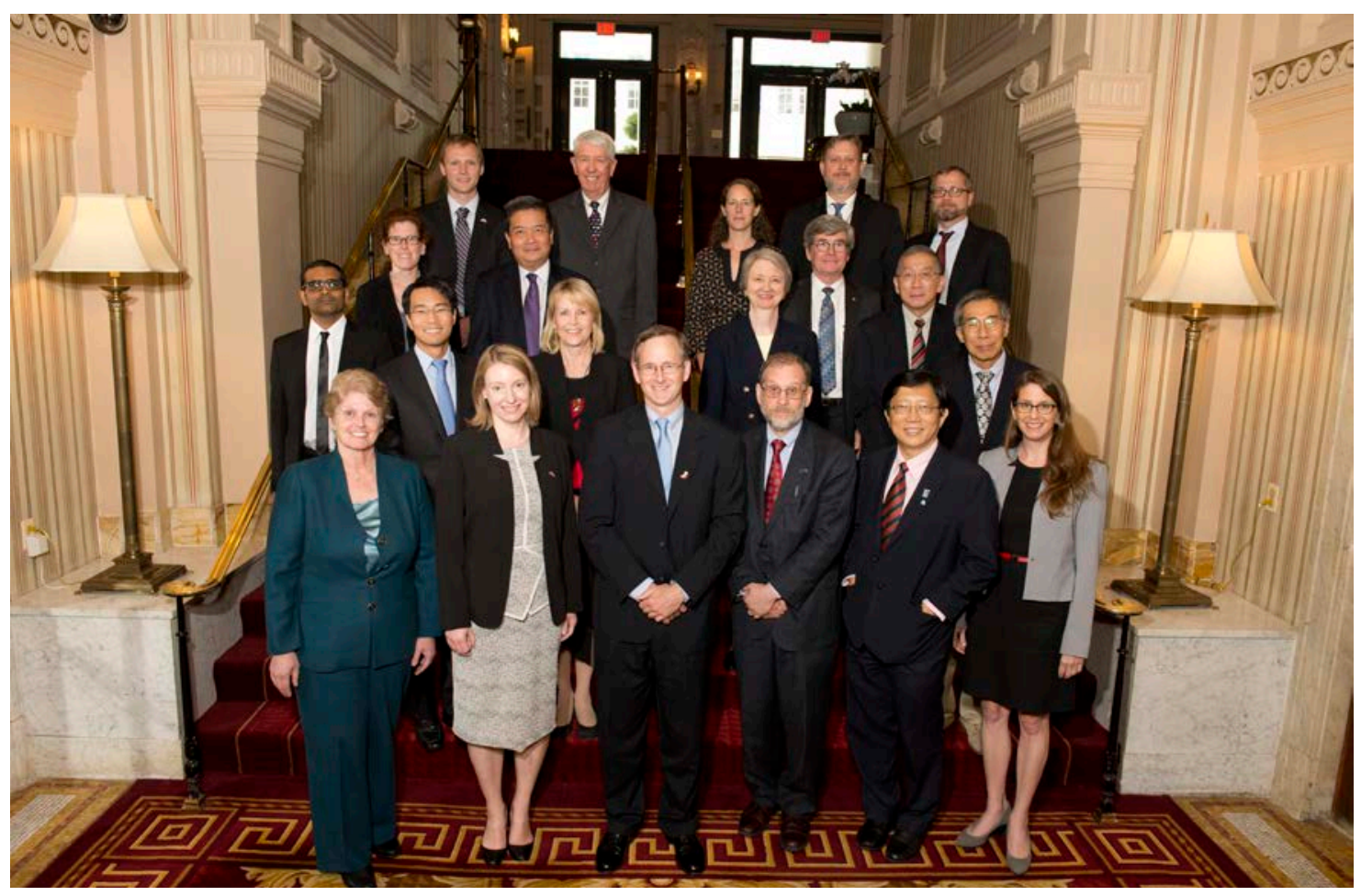

Singapore-US Strategic Dialogue on Biosecurity: Participants

Front row (left to right): Barbara Johnson, Gigi Kwik Gronvall, Thomas Inglesby, Seth Carus, Teck-Mean Chua, and Anita Cicero.

Second row (left to right): Krishna Khanal, Vernon Lee, Annelies Wilder-Smith, and Kwa Chong Guan. Third row (left to right): Julie Fischer, Lee Fook Kay, Noreen Hynes, Kenneth Bernard, and Tikki Elka Pangestu. Fourth row (left to right): Ryan Morhard, James LeDuc, Meghan Rasmussen, William Hostyn, and Shane Smith. 


\section{Introduction}

In June 2014, the UPMC Center for Health Security hosted the first-ever Track II biosecurity dialogue between the United States and Singapore. The meeting took place in Washington, DC, and was supported by the Project on Advanced Systems and Concepts for Countering WMD (PASCC) of the Center on Contemporary Conflict, sponsored by the US Defense Threat Reduction Agency (DTRA).

The purpose of this meeting was to explore the biosecurity landscapes of the US and Singapore, study policies and frameworks for addressing biological risks, encourage partnerships between the two nations towards building resilience against biological threats, and share lessons learned and best practices for enhancing biosecurity. The dialogue was attended by participants representing academia, government, and industry in both countries, and included experts in biosecurity, biosafety, global health security, the life sciences, biodefense, and regional security.

The meeting consisted of six plenary sessions, each preceded by opening remarks delivered by select participants. These remarks, in turn, set the stage for subsequent group dialogue. Broadly, topics of discussion included the emerging roles of the life sciences, biosafety practices, dual-use research of concern, international frameworks for handling biological threats, and regional security contingencies. Sessions were interspersed with presentations by speakers currently or formerly affiliated with the US Departments of Defense and Homeland Security, the White House, and Singapore's Ministry of Foreign Affairs.

The dialogue proceeded openly, with enthusiastic participation from both countries' attendees. Participants and meeting observers were impressed with the quality and content of each session, and commented on the value of convening stakeholders from various sectors to tackle the critical biosecurity issues of today. Participants also expressed interest in deepening the discussion through future meetings in order to further promote dialogue and collaboration between the US and Singapore.

The following sections describe key themes and findings from the meeting discussions.

\section{Findings}

\section{Perceptions of the Biosecurity Threat}

Singapore's perception of biological threats to their security is shaped by their experiences during the SARS pandemic of 2003, the specter of avian influenza, and geography-Singapore is an island with heavy, daily traffic as a result of trade, tourism, and workers from Indonesia and Malaysia. The American perception of biological threats includes the threat of natural outbreaks but is much more heavily influenced by the experiences of anthrax in 2001, and the ongoing future potential for deliberate biological attacks. While Singapore's emphasis has been on natural biological threats, Singapore sees the need for, and has invested in, detection and defense capabilities for biosecurity threats.

During this first meeting, participants emphasized that each nation's biosecurity policy is primarily driven by perception of the biosecurity threat -- as shaped by historical experiences, regional issues, 
perceived risks, national priorities, current events, and other dynamics. In this respect, perceptions of the biosecurity threat in the US and Singapore naturally have different dimensions.

Participants from Singapore highlighted that vulnerability to naturally occurring infectious disease threats, as evidenced by experience during the Severe Acute Respiratory Syndrome (SARS) pandemic of 2003 , is the primary driver for high-level policymakers with regard to biological threats. Singapore was aggressive in their response to SARS, establishing temperature screening at airports, serving quarantine orders to nearly 8,000 people, placing over 4,000 on daily telephone surveillance, and spending millions to bolster hospital capacity. ${ }^{1}$ Ultimately, SARS infected 238 Singaporeans, killing $33 .{ }^{1}$ Subsequent responses to other potential epidemics have been similarly serious; for example, in response to the threat of MERS, Singapore has reinstated temperature checks for passengers arriving at Singapore's airports from countries in the Middle East. ${ }^{2}$

Singapore is situated the heart of the most prominent cases of emerging and reemerging infectious diseases; a participant humorously labeled the region "Avian Influenza Central." Though Singapore is a city-state and its citizens do not typically farm animals, the practice remains common in neighboring countries. Indeed, throughout the greater Asian region, large numbers of animals live in close proximity to humans, presenting such communities with the challenge of contending with potential infectious threats; in turn, vectors such as trade and travel increase the likelihood of these threats materializing on Singaporean soil. According to a participant, Asia is home to $60 \%$ of the world's population, but also $60 \%$ of the global pig population and $40 \%$ of the global chicken population.

Furthermore, as one of the leading hubs of the global economy, Singapore sees large numbers of people moving across its borders daily, many coming from less economically developed areas. For example, over 300,000 Malaysians commute to work across the border daily. ${ }^{3}$

Participants identified several biosecurity threats that are of shared concern to both the US and in Singapore. These threats have the potential to endanger human health, overwhelm emergency response mechanisms, and defy existing regulatory systems, and include naturally occurring outbreaks of disease, outbreaks stemming from laboratory accidents, and the worsening problem of antimicrobial resistance. In recent years, rapid population growth, changing climates, and geopolitical turmoil have amplified these challenges.

A number of US participants in the dialogue noted that while there is broad agreement around the importance of the above challenges, disease resulting from the intentional manipulation of biological agents and systems may present equally compelling or even greater challenges in terms of prevention, detection, and response. Threats falling under this category include acts of bioterrorism and biological weapons attacks, the nefarious manipulation of dual-use research of concern, and the risks associated with emerging and untested biotechnologies. US participants discussed how the biosecurity threat perception in the US encompasses defense against intentional use of infectious disease as a weapon of terror. This underlying biosecurity principle in the US is linked to its national experiences post 9/11, including the anthrax letter attacks; to its own former bioweapons program, which was discontinued in 
1969; to encounters with the offensive programs in the former Soviet Union and in Iraq; and to growing worldwide interest in WMD terrorism.

Singaporean participants recognized that, as a global power, the risk of bioterrorism in the US may be higher than it is in their country, where, according to one participant, many counterterrorism experts believe the risk is "very low." Still, as a US participant remarked, the "biological weapons may be a lowprobability threat in Singapore, but it is not a 'no-probability' threat." The Singaporean participants agreed, noting that Singapore's strong economy and support of the US and the West can sometimes make it "stick out like a sore thumb" in the region. Singaporean participants believe that these particular qualities could heighten the risk of Singapore becoming the target of an attack, perhaps one orchestrated by known terrorist groups in other countries. To this point, Singaporean participants stated in different ways throughout the dialogue that "Singapore can't be safe unless the region is safe."

\section{"We cannot act alone in Singapore. We need to work with the USA and in a regional network."}

Singapore has acted on this perspective by maintaining robust institutions and activities dedicated to defense, scientific research and development, and health, and has also invested in assets to enhance biosecurity and biodefense capabilities. In recent years, for example, Singapore has established early warning and detection systems and procured monitoring technologies to support ongoing efforts in biodefense. ${ }^{4,5}$ Similarly, Singapore's Defense Science Organization and Defense Science Technology Agency have supported numerous research and development initiatives and enhanced biological threat detection capabilities among military forces, respectively. ${ }^{6}$ The US has analogous and expansive programs that span the Department of Defense, The Department of Health and Human Services, and the Department of Homeland Security.

Notwithstanding the differences in each nation's motivations to strengthen biosecurity, all participants recognized that strengthening biosecurity was a priority for their respective countries, and that regardless of whether infectious disease outbreaks are natural or intentional, many of the required capabilities to prepare, detect, and respond are mutually beneficial. Therefore, the participants believed, the US and Singapore are natural partners on this issue.

\section{Dangerous Pathogens and Biosecurity Regulations}

\section{Like the US, Singapore maintains a robust set of legal and regulatory mechanismsto address the risks associated with handling and shipping dangerous pathogens, as well as coordinating laboratory oversight.}

Singapore and the United States have instated strict regulations governing biological research that utilizes select agents, or pathogens with the potential to pose severe threats to public health and safety. ${ }^{7-9}$ US participants acknowledged the successes of such regulations, citing increased awareness of 
where high-risk pathogens are being used, as well as greater knowledge among scientific personnel regarding safety and security.

However, some US security requirements were seen as misguided. For example, one participant remarked, "It doesn't make sense, scientifically or security-wise, to count vials. The whole concept of counting pathogens doesn't make sense." Counting vials may also result in cultures losing their viability, another serious scientific challenge.

Believing that "the whole idea of scientific exchange is hampered by these security regulations," US participants suggested that cost-benefit analyses of safety and security regulations are needed.

According to one participant, "security costs alone -- armed guards, etc. -- can cost a laboratory $\$ 2.3$ million per year." These regulations were seen as a significant enough burden for scientists to opt to work in alternative areas of biological research to avoid the regulations all together. Furthermore, US participants insisted that because regulations in the US are so much stricter than those in other nations, US scientists are unable to effectively partner with scientists from nations with less stringent parameters. Therefore, "the regulations have the unintended effect of [isolating] US scientists from the global community."

\section{"The bio-revolution will have profound impacts \\ on the global economy, as well as national and international security."}

Most of the biological research done in Singapore is focused less on basic research and more on commercializing products, including those supporting diagnostics and detection. Ultimately, "there aren't many labs [in Singapore] that work on frightening pathogens." Laboratories that do are concentrated within Singapore's defense agency, and are subject to restrictions similar to those enforced in the US.

Participants from both countries believed that transparency, personal engagement, and building confidence between partners can be as effective as regulations aimed at ensuring security.

\section{National Biosecurity Challenges and Potential Benefits Emanating from Rapid Growth of the Life Sciences}

US and Singaporean participants shared concerns that powerful advances in the life sciences will inevitably lead to increased biosecurity risks. However, they also shared the view that the life sciences will play an important role in mitigating risks and producing solutions to those challenges. There is a need to strengthen both formal and informal networks between countries and across sectors in order to manage this issue judiciously. One participant posited that the life sciences have entered a state of enormous transformation, with technologies such as synthetic biology and proteomics converging to create an impact likely to surpass that of the information technology revolution. The changes wrought by this "bio-revolution" hold major implications for the global economy as well as for international security. Despite the risks associated with current practices in biological research and biotechnology 
development, participants acknowledged the role of the life sciences in mitigating risks and producing solutions to the challenges they pose. The Human Genome Project was identified as an example of an endeavor that fundamentally changed the practice of biology by underscoring teamwork among scientists as a major driving force behind innovation.

Participants discussed issues surrounding the "dark side" of the bio-revolution. Research in synthetic biology, for example, carries inherent dual-use risks, given that both beneficial and illegitimate research pursuits may involve manipulation of living organisms. Participants pointed to lower barriers of access to laboratory equipment, biological agents, and genetic information as factors contributing to this risk. The issues surrounding dual-use research of concern are particularly salient in the US, given the 2012-2013 controversy over whether to publish the methodological details of the so-called gain-of-function experiments with the H5N1 avian influenza virus. This issue has not had as much traction in Singapore, in part because this type of research is not being conducted there.

Singaporean participants acknowledged that they benefit from the small size of its research community, stringent biosafety requirements, and robust legislative regulation. That said, participants from Singapore believed broader frameworks must be in place governing dual-use research of concern, generally. All participants saw this as a significant challenge, noting that "there is no one-size-fits-all framework for the diversity of new sciences."

Participants agreed that embracing advances in the life sciences is essential to realizing the full benefits of the bio-revolution while also forestalling potential scientific abuses. However, researchers in both the US and Singapore face numerous bureaucratic and financial obstacles that often stifle scientific innovation.

Singaporean participants cited some challenges currently faced by Singaporean researchers, such as a focus on acquiring "new knowledge." Many research efforts in Singapore are directed towards generating explicitly new knowledge and products, to the exclusion of understanding existing products and systems, a phenomenon described as "a striking imbalance." Another barrier addressed was a focus on team-based research. In contrast to the US, much of the research carried out in Singapore is conducted in teams and organized around a national mission, a practice that stifles scientists who prefer to work independently. This approach also extends to funding practices. One participant stated that demonstrating nationwide collaboration and producing deliverables with high commercial potential is essential to winning grants in Singapore. Furthermore, certain grants may only be spent in-country, which complicates efforts to collaborate with regional partners.

The Americans identified several problems of particular concern in the US, including: lengthy research and development timelines; a lack of government support for research projects, particularly those aiming to tackle long-term problems; and over-reliance on single-investigator grants that reward established researchers, versus a team-based approach that may favor newcomers and younger scientists. Participants emphasized the dearth of opportunities and funds for young scientists in the biorevolution, remarking that the field currently "[starves] young, innovative people," and suggesting that up-and-coming researchers have little incentive to pursue careers in the life sciences. 
Members of both countries cited commercialism as a significant barrier to innovative research. One participant remarked that investment in research efforts aimed at improving applications of existing knowledge yields greater benefits than allocating funds towards acquisition of new knowledge. The Americans and Singaporeans also agreed that careerism often inhibits scientific progress, with one participant noting that the incentives of money and professional advancement have given rise to highly secretive, non-collaborative research environments. Participants from both sides asserted the need for and importance of "resilient formal and informal networks between countries, among scientists that cross national borders."

Given the benefits of the biosciences to national security and health in both countries, sharing best practices for funding, organizing, and practicing science could prove to be a rewarding endeavor. Continued collaboration and deepening understanding of these issues should be a priority for both countries.

\section{Biosafety and Biosecurity Infrastructure and Mitigating Against Insider Threats}

There are moves in both countries to professionalize the biosafety field, as evidenced by accreditation programs, and shared concerns about the difficulty in deterring the insider threat. There are also similar perspectives on the sustainability of already-built, high-level containment laboratories within lower-income countries, as these facilities require funding for maintenance and training well after the laboratory has been built. Efforts should be made by both countries and other donor nations to adapt biosafety standards that account for the infrastructural capabilities (e.g. reliable power grids) of a given nation. As a strong proponent of biosafety, Singapore is also interested in helping their neighbors achieve similarly high levels of biosafety. They recognize that a chain is only as strong as its weakest link in the region.

Participants addressed American and Singaporean approaches to enhancing and enforcing biosafety measures in research laboratories, identifying the steps taken to conduct risk assessments, implement safety protocols, and handle regional biosecurity threats. In recent years, for example, Singapore has established a robust set of legal and regulatory mechanisms for accomplishing these objectives. Notable among these is the Ministry of Health's Biosafety Team, a regulatory policy branch that works with the Agri-Food and Veterinary Authority to oversee the import and transshipment of select biological agents and toxins. ${ }^{10}$ The Team also enforces the provisions of the Biological Agents and Toxins Act of 2005, which prohibits the illicit use and transportation of biological agents and toxins. ${ }^{10}$

Attendees from both nations agreed that building sustainable laboratories is an important challenge facing scientific communities worldwide, particularly for those in lower-income countries that might lack the resources to maintain advanced laboratory equipment. An American participant asserted that the approach of constructing larger, more advanced laboratories often fails in Southeast Asia, and that workers in BSL-1, BSL-2, and clinical laboratories may run a greater risk of acquiring infections than those working in higher-level containment facilities.

Participants noted that high-level research facilities have sometimes functioned as status symbols of a nation's wealth, and that the construction of such labs is not always driven by need. One Singaporean 
participant, however, affirmed the value of higher-level biocontainment labs in mitigating outbreaks involving uncharacterized pathogens, citing overwhelmed hospital laboratories during the SARS outbreak of 2002-2003. An American attendee pointed out that the scientific community often experiences "collective amnesia" about the resources required to sustain large laboratories, noting that limited grandfathered funding often supports new facilities in their early years. Once these funds dissipate, however, these facilities are either forced to close or operate at a lower level of safety. The Singaporeans addressed the utility of donor assistance to low-income countries, highlighting the need for local personnel to assume responsibility for donor-sponsored research facilities once outside funding dries up.

\section{"The strength of a chain is measured by its weakest link. To stay safe, we must help protect our neighbors."}

Participants underscored the importance of evidence-based approaches to enhancing biosafety. An American participant commented on the dearth of data on laboratory sustainability in both countries, noting that current biosafety protocols adopted at institutional or national levels in high-income laboratories result from years of laboratory practice. These protocols are then promulgated outward to newer laboratories in both high- and low-income countries. While technically effective, such practices may be unsustainable in poorly resourced facilities. The participant also acknowledged the risks of advocating for less biosafety, but maintained that certain measures are simply infeasible in regions of unrest and instability, and pointed out that alternative methods of handling pathogens are often more economical and just as effective as the methods employed in high-income laboratories. The Singaporeans concurred, suggesting that while a "copy-and-paste" or "one-size-fits-all" approach to developing biosafety standards might yield short-term success, such practices would likely prove unsustainable in the long term. Rather, sustainable biosafety standards should account for the unique cultural norms, research priorities, and infrastructural capabilities (e.g. reliable power grids) of a given nation.

Commenting on an insider threat potential related to bioterrorism, one Singaporean attendee observed that a determined actor could overcome even the most robust biosafety and biosecurity mechanisms, emphasizing the importance of background checks for laboratory personnel. Another Singaporean participant identified "third-generation terrorists" as potential biosafety threats. Such individuals, often well-educated young professionals, may be highly computer-literate and could gain access to infectious disease agents. The Americans agreed that any scientist capable of entering a laboratory is also capable of accessing potentially hazardous biological materials. Therefore, in addition to hiring reliable workers, fostering positive cultures in laboratory settings and building productive relationships among personnel are also key components of promoting biosafety. An American participant also advocated for instituting bioethics and biosafety training for student scientists in the US, pointing out that Singapore's workplace development agency is already devising biosafety accreditation electives for biosafety professionals and coordinators. 
Nearly half of the world's population resides in the Asia Pacific region, which is also a major hotbed for emerging infectious diseases. As such, the region is of strategic interest with respect to matters of biosafety and biosecurity. In comparison to other Asian-Pacific nations, Singapore has already implemented higher standards for biosafety practices. A Singaporean participant noted that despite the differing capabilities, resources, and cultures between laboratories in high- and low-income countries, these facilities must often contend with the same types of outbreaks. Furthermore, Singapore's role as an Asian Pacific leader in research and development has also put Singapore in a critical position in the region with respect to biosafety. A Singaporean participant remarked, "The strength of a chain is measured by its weakest link. To stay safe, we have to protect our neighbors."

Singaporean and US attendees discussed possible regional approaches to building biosafety. There was broad recognition of the important role that the World Health Organization (WHO) plays in developing regional frameworks, noting its expertise, legitimacy and political neutrality. Individuals from both sides also expressed skepticism about the appropriateness of WHO playing the role of a professional standards organization on this issue. It was widely agreed that while regional-scale health and science endeavors often require WHO involvement to succeed, WHO in turn requires strong member state support. One American suggested that WHO create toolboxes to guide countries in developing and implementing standards tailored to their individual biosafety needs and priorities.

\section{Bridging Security and Health}

Participants in both countries affirmed the importance of close collaboration between the health and security communities in responding to biosecurity threats. Singapore is not yet a member of the Global Health Security Agenda, a 2014 White House initiative, but during the meeting, dialogue participants were invited by ASD Weber to consider joining the GHSA. Participants shared sentiments about the need to balance vertical health programs that target the specific objectives in the GHSA, International Health Regulations (IHR) and the Millennium Development Goals (MDG) with the need to build horizontal capacities that enable health service delivery.

The attendees discussed frameworks for sharing information and strategies for managing biosecurity risks of international concern, including the Global Health Security Agenda (GHSA), an initiative aimed at securing the world from infectious disease threats; the International Health Regulations (IHR), a series of obligations and guidelines for managing health threats with associated transnational risks; and the Millennium Development Goals (MDG), a set of directives for resolving health, developmental, socioeconomic, and educational barriers threatening quality of life. The majority of the discussion during this session centered on the strengths of and potential challenges for the recently-released GHSA, the links between GHSA, IHR, and MDG, and the implications of these frameworks for addressing global health security concerns.

The Singaporean participants observed that many of the objectives outlined in GHSA align with various IHR mandates and guidelines, and noted that additional funding for WHO could be the key to accomplishing some of these goals. However, one participant also pointed out that the goals of GHSA do not appear to align as neatly with MDG, which aims to enhance state capacities to deliver universal healthcare. The Singaporeans agreed that the GHSA could help sustain MDG - specifically, by 
encouraging nations to take steps to reduce child mortality and combat HIV/AIDS, malaria, and other diseases - but expressed concern that GHSA could also lead to "initiative fatigue" among countries experiencing the double burden of both chronic and infectious diseases. Singaporean participants commended the GHSA and believed that Singapore was well-positioned to contribute, joining the more than 30 other nations already participating. Attendees also discussed the US role as a leader in GHSA implementation and explored some of the operational challenges associated with accomplishing GHSA objectives such as maintaining communication between the health and security sectors across different geographic regions. Participants from both sides also stressed the need for appropriately scaled metrics to evaluate progress made under GHSA.

Though GHSA has renewed many nations' commitments to solving critical global health security problems, implementing activities in response to these problems remains a challenge. Specifically, participants addressed the need to balance the interests of vertical and horizontal health programming. Vertical programs, which target specific health conditions, are typically implemented in poverty-stricken regions with fragile healthcare delivery systems and high disease burdens stemming from infectious disease epidemics. ${ }^{11}$ Horizontal programs, meanwhile, offer general services (often preventive in nature) aimed at tackling a population's prevalent health conditions. ${ }^{11}$ Participants from both sides noted the apparent ubiquity of vertical programming in developing regions and acknowledged the difficulties inherent in evaluating non-vertical programs, but still underscored the need for effective "bottom-up" approaches to global biosecurity and biosafety problems. One participant noted that funding such programs is less typical for Singapore; rather than financing other countries directly, Singapore instead encourages other states in the region to build health service delivery systems and supports them through trainings and other supplementary mechanisms. Members also highlighted the need for greater international advocacy for specific health security issues, stating that it is often difficult to "convince people at the top that these issues matter."

\section{"Building collaboration across different sectors is the key to ensuring sustainability."}

Cross-sector collaboration between health and security professionals is necessary for implementing successful whole-of-government and societal responses to biosecurity challenges. One participant noted that it is critical for states to analyze their existing health capacities and consider how to involve players from multiple sectors, pointing out examples of how militaries in many nations direct emergency operations centers (EOC), but fail to engage ministries of health in EOC activities. Still, the participant noted that the SARS outbreak in Singapore also demonstrated the Ministry of Health's limitations in responding to major surge events, and maintained that the military is best-equipped to run EOCs and emergency exercises. An American participant agreed, referencing the expertise of many militaries in planning, budgeting for, and implementing emergency operations. On the issue of EOC capacities, another US participant cautioned against replicating the American EOC model in lower-income states, stressing the importance of building sustainable emergency response infrastructures. The participant also suggested exploring options for more durable funding mechanisms for emergency efforts, such as depositing operating costs to support at-risk nations. 
Building Biosecurity in the Asia-Pacific Region

The US and Singapore have shared interests in building the biosecurity capacity of Singapore's neighbors.

With respect to areas where Singapore and the US might work together to resolve Asia-Pacific regional contingencies, participants from both countries recognized the importance of collaborative relationships between scientists, public health practitioners, and the security community across the region. On this point, one US participant was persuasive in asserting that "the name of the game, and the solution to all the problems, whether it is natural diseases or terrorism, or a deliberate biothreat, lies in the creation of very resilient formal and informal networks between countries, amongst scientists, that cross national borders - and we aren't nearly as good at that as we need to get." Another participant framed the task that both countries confront: "Both nations share the same vulnerabilities. Both share an interest in building capacity of weak neighbors and bridging gaps with strong neighbors."

"The name of the game, and the solutions to all the problems, whether it is natural diseases or terrorism, or a deliberate biothreat, lies in the creation of very resilient formal and informal networks between countries, among scientists, that cross national borders."

Singaporean participants viewed Indonesia and Malaysia as its closest regional collaborators, noting that lapses in biosecurity in those nations would inevitably impact Singapore, and vice-versa. Although practitioners at the "operational level" in these nations enjoy good relationships, there was less confidence that political officials in the three countries could say the same. In fact, outside of

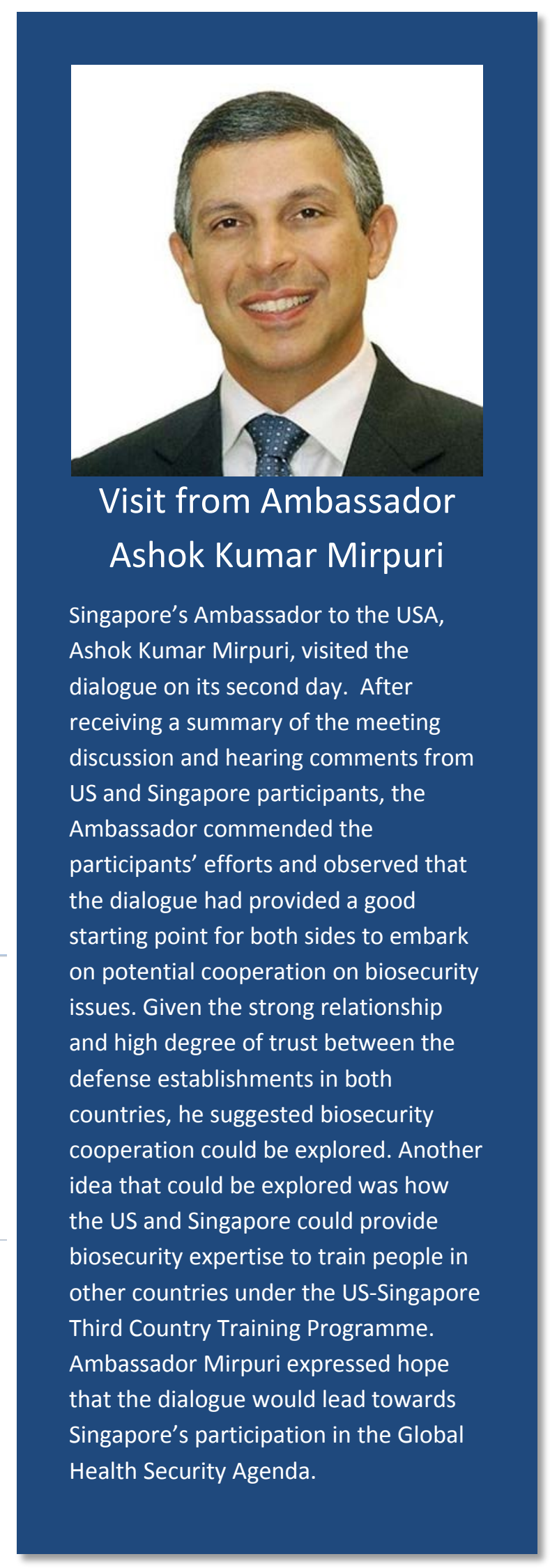


dedicated meetings, "these officials may never even speak to each other." Singaporean participants expressed a desire to provide expert guidance to build capacity in the region, but perceived a general lack of political interest in doing so among the three nations. Further, among these nations, it was believed that, "when it comes to things we can't agree on, these things just get swept under the rug."

Singaporean participants conveyed confidence in their country's relationship with the United States and viewed US activity in the region as a net-positive. Some encouraged the US to adopt more inclusive policies, particularly with respect to Indonesia and China. US participants recognized this challenge, adding that "US programs are becoming increasingly creative and aware of regional ties, but that "bilateral relationships are managed in ways that don't address cross-border risks."

Singaporean participants observed that there remains some distrust and confusion in the region about US motivations surrounding biosecurity stemming from the "viral sovereignty" debate in the mid-2000s. During that time, Indonesian's then Minister of Health asserted that H5N1 viral samples taken from Indonesia were being used by foreign pharmaceutical companies to develop a vaccine that would presumably be unaffordable to Indonesia and other low income countries. ${ }^{12}$ The controversy ultimately resulted in the closure of NAMRU-2 in Indonesia.

Some Singapore participants also saw US activity in the region as more focused on "security" than "health." On this point, one US participant reminded the group that a key member of the Al Qaeda biological weapons program was a former member of the Malaysian army, and that Al Qaeda plotted terrorist activity against Singapore. All viewed increased tension in the South China Sea as an indicator of potential threats and a reminder of the importance of forming strong relationships and building regional biosecurity capacity to address biological threats of all kinds, naturally-occurring and deliberate.

\section{Moving Forward to the Next Strategic Dialogue}

There is a strong recommendation by participants to make this dialogue multilateral and to include Malaysia and Indonesia. The goal will be to have a multilateral dialogue by 2015 . For the next meeting, shared areas of concern will be developed into agenda topics, including perspectives on bioterrorism risk assessments.

After reflecting positively on the productive meeting, participants turned their attention to the next meeting, to take place in Singapore in the fall, and to subsequent dialogues in the years beyond. Participants discussed possible subjects of discussion in the fall, including risk assessment, risks emanating from gain-of-function research, sharing best practices relating to responding to white powder incidents that continue to plague both nations, public-private partnerships in biotechnology, trade issues impacting public health, and exploring ideas to broaden access to technologies supporting biosecurity. Many in the group also expressed a desire for the group to collectively participate in activities with the potential to produce "actionable recommendations," such as a tabletop exercise. All participants also hoped to use these forums and these new relationships as a platform to broaden capacity in the region, eventually adopting a more multilateral approach to include Singapore's neighbors. 


\section{Conclusions}

The inaugural meeting of the Singapore-US strategic dialogue on biosecurity yielded the following important conclusions:

1. There are differences in biosecurity priorities between the two countries. While there is broad agreement on the importance of biosecurity as a national issue, the two countries have different top-level concerns. Singapore's major concerns are largely related to infectious disease outbreaks with epidemic potential, as Singapore is an island with heavy, daily traffic as a result of trade, tourism, and workers entering from Indonesia and Malaysia. Singapore is also cognizant of terrorist group activities in the region. It sees the need for, and has invested in, biodetection and biodefense capabilities, though many Singaporean security experts perceive the bioterrorism threat to be low. ${ }^{4,5}$ The US, shaped by its own experiences with terrorism and disease outbreaks, has serious national concerns regarding both deliberate biological threats as well as the threats posed by naturally occurring epidemic disease.

2. Singapore and the US should build on their existing, strong relationship to strengthen biosecurity in the Asia-Pacific region. Singapore and the US share concerns about the seriousness of biological threats to their respective nations, and have clear reasons for partnership and collaboration. A deepened partnership would have value for both countries.

3. The Global Health Security Agenda (GHSA), a 2014 White House-led global initiative, provides an opportunity for enhanced cooperation between the US and Singapore. Singapore is not yet a member, but was invited to participate in the GHSA by Assistant Secretary Weber at the meeting. Singaporean participants were supportive of this possibility and noted that collaboration between the health and security communities, an integral component of the GHSA, is already quite common in Singapore.

4. Singapore and the US share interests in biosafety and biosecurity training, and are concerned about the maintenance of biosafety high-containment laboratories, particularly in lessresourced nations. Singapore's perspective is that a chain is only as strong as its weakest link. The country therefore sees it as their responsibility, and important for their own protection, to help their regional neighbors achieve high levels of biosafety and biosecurity. Like the US, Singapore is moving to professionalize and expand the biosafety field. Improving biosecurity and biosafety also includes planning in both countries to reducing the insider threat.

5. Singaporean participants strongly encouraged expanding this strategic dialogue to become multilateral in order to engage other nations critical to biosecurity and biosafety in the region and to invite more of a diversity of views. It was noted that the debate over "viral sovereignty" and the closure of the NAMRU-2 lab in Indonesia has resulted in an ongoing level of regional distrust -- both of the US and Singapore. Much can be done constructively to engage with countries in the region on biosecurity issues. The goal will be to include Indonesia and Malaysia in a strategic dialogue on biosecurity with the US and Singapore, starting in 2015. 


\section{Appendix A: Agenda}

June 10

\section{Session 1 \\ General strategic threat perceptions about biosecurity}

During this roundtable discussion, attendees will explore respective national perspectives on biosecurity. Is there agreement on primary biosecurity threats and risks? Are there shared perceptions of the importance of biosecurity? This session will also explore historical contexts underlying biosecurity practices in both countries.

\section{Session 2:}

Emerging life sciences and technology: challenges and opportunities for biosecurity

Emerging biotechnologies are widely believed to have positive effects for medicine and health, and for national economies. These powerful developments are accompanied by the potential for both better medical countermeasures as well as increased risks for the potential for new weapons and for consequential accidents. How do the US and Singapore see the future of biotechnology changing the ability to develop medical countermeasures, as well as the potential for increased risks, and how should the US and Singapore evaluate these developments separately and together? In light of these trends, how should each country go about making strategic investments in biosecurity?

\section{Perspectives in Biosecurity:}

Remarks and discussion led by Dr. Richard Danzig, Member, Defense Policy Board; Chairman of the Board of Directors, Center for a New American Security

\section{Session 3:}

Safety and security: overlapping mandates and different strategies

Biosafety and biosecurity are often working together, and this session will focus on the increased formalization of biosafety in Singapore and the US. What are the most pressing biosafety issues in Singapore and in the US, and how does each view biosafety problems on the horizon? 
June 11

Presentation on US biological research governance: Dr. Gigi Kwik Gronvall

\section{Session 4:}

Balancing restrictions and promotion of biotechnology; oversight of research

Singapore passed biosecurity legislation in 2006 that put in place biological agent and toxin security measures similar to what the US has for biological select agents and toxins (BSATs). Other topics of discussion include dual-use research concerns and governance of research. In this session, attendees will also discuss other strategies for identifying and addressing risks in biological research.

\section{Session 5:}

Productive engagement: new means for strengthening information sharing, risk management strategies for biosecurity and responding to public health emergencies of international concern

This discussion will explore formal and less-formal opportunities to collectively and collaboratively reduce the threat of emerging infectious diseases such as MERS and new influenza viruses, deliberate and accidental misuse of biological research, and opportunities to increase the likelihood of early intervention, attribution, and resolution of an outbreak. The International Health Regulations (2005), Global Health Security Agenda, and Biological Weapons Convention each prioritize efforts to strengthen international efforts to prevent, detect, and respond to infectious disease threats, and can offer formal opportunities for collaboration.

\section{Perspectives on Biosecurity}

Remarks and discussion led by Mr. Andy Weber, Assistant Secretary of Defense for Nuclear, Chemical, and Biological Defense Programs at the US Department of Defense

\section{Session 6:}

Asia-Pacific Regional Contingencies

Examining areas where Singapore and the US may have to work together to resolve regional contingencies with biosecurity implications. This discussion will also consider the role of collaborative relationships between scientists, public health practitioners, and the security community.

\section{Session 7:}

Topics for the next meeting, and wrap up

Discussion of what we have heard over the course of 2 days, and suggestions for what should be focused on for the fall meeting in Singapore. 


\section{Appendix B: Participant List}

Singapore

Teck-Mean CHUA, DMD

President, Asia-Pacific Biosafety Association

Consultant, Biorisk Management, Temasek Laboratory

Krishna KHANAL, MSc, MBA

Research Analyst, International Center for Political Violence and Terrorism Research, RSIS

KWA Chong Guan, MA

Senior Fellow, S. Rajaratnam School of International Studies (RSIS)

Adjunct Associate Professor, National University of Singapore

LEE Fook Kay, PhD

Chief Science and Technology Officer, Ministry of Home Affairs

Vernon LEE, MBBS, PhD, MPH, MBA, FAMS

Head, Biodefense Center, Singapore Armed Forces

Associate Professor, National University of Singapore

Advisor, Ministry of Health

Ashok Kumar MIRPURI, MA (speaker)

Singapore's Ambassador to the United States of America

Tikki Elka PANGESTU, PhD

Visiting Professor, Lee Kuan Yew School of Public Policy, National University of Singapore

Former Director of Research Policy \& Cooperation, World Health Organization

Annelies WILDER-SMITH, MD, PhD, DTM\&H, MIH, FAMS, FACTM

Professor, Lee Kong Chian School of Medicine, Nanyang Technological University

President-Elect, International Society of Travel Medicine

\section{United States}

Kenneth BERNARD, MD, USPHS (Ret.)

Special Advisor, White House National Security Council

Former Senior Political Adviser to the Director-General, World Health Organization

Seth CARUS, PhD

Deputy Director, National Defense University

Elizabeth CAMERON, PhD (speaker)

Director, Countering Biological Threats, White House National Security Council 
Richard DANZIG, JD, PhD (speaker)

Member, Defense Policy Board, President's Intelligence Advisory Board

Chairman, Center for a New American Security

Former Secretary, US Navy

Julie FISCHER, PhD

Associate Professor, Co-Director of Global Health Security Projects, George Washington University

Noreen HYNES, MD, MPH

Director, Geographic Medicine Center of the Division of Infectious Diseases, Johns Hopkins University

Barbara JOHNSON, PhD, RBP

Director, Biosafety Biosecurity International

James LE DUC, PhD

Director, Galveston National Laboratory, University of Texas Medical Branch

Tara O'TOOLE, MD, MPH (speaker)

Former Undersecretary for Science and Technology, US Department of Homeland Security

Andrew WEBER, MSFS (speaker)

Assistant Secretary of Defense for Nuclear, Chemical, and Biological Defense Programs, US Department of Defense 


\section{Appendix C: References}

1. Tan CC. SARS in Singapore -- key lessons from an epidemic. Ann Acad Med Singapore. 2006;35(5):345-349.

2. Spyerkman K. Temperature checks at S'pore airports from Sunday. Channel News Asia. 2014. http://www.channelnewsasia.com/news/singapore/mers-temperature-checks/1107836.html. Accessed July 3, 2014.

3. Liew CT. Economic reform needed to tackle exodus of Malaysians to Singapore. The Malaysian Insider. June 21, 2014. http://www.themalaysianinsider.com/sideviews/article/economicreform-needed-to-tackle-exodus-of-malaysians-to-singapore-liew-chi. Accessed July 3, 2014.

4. Universal Detection to supply Singapore with biological detectors. Homeland Security News Wire. July 1, 2011.

5. Dolnik A. Singapore and the Four D's. CSIS2005.

6. Dolnik A. Biological Threat Reduction Baseline: Singapore and the Four D's. Washington, DC. September 2005: http://csis.org/files/media/csis/pubs/050913 dolnik.pdf. Accessed July 3, 2014.

7. Parliament of Singapore. Biological Agents and Toxins Act 2005 (No. 36 of 2005). Entered into force January 3, 2006.2005.

8. Dias MB, Reyes-Gonzalez L, Veloso FM, Casman EA. Effects of the USA PATRIOT Act and the 2002 Bioterrorism Preparedness Act on select agent research in the United States. Proc Natl Acad Sci U S A. May 25;107(21):9556-9561.

9. Centers for Disease Control and Prevention. Select Agent Registry. 2014; http://www.selectagents.gov/Select\%20Agents\%20and\%20Toxins\%20List.html. Accessed May 16, 2014, 2014.

10. About Us. Ministry of Health Biosafety website. 2010; https://www.biosafety.moh.gov.sg/home/page.aspx?id=55. Accessed July 3, 2014.

11. Elzinga G. Vertical-horizontal synergy of the health workforce. Bulletin of the World Health Organization. 2005;83(4).

12. Ear S. Towards effective emerging infectious disease surveillance: Cambodia, Indonesia, and NAMRU-2. Defense Threat Reduction Agency's Office of Strategic Research and Dialogues and Naval Postgraduate School. 2011. 